\title{
Characterization of serum protein fractions of dogs naturally infected with Ehrlichia canis or Anaplasma platys associated with uveitis
}

\author{
Nimsuphan, B. ${ }^{1,4}$, Prasroedsang, S. ${ }^{1 *}$, Kengradomkij, C. ${ }^{1}$, Thayananuphat, A. ${ }^{2,4}$ and Kromkhun, P. ${ }^{3}$ \\ ${ }^{1}$ Department of Parasitology, Faculty of Veterinary Medicine, Kasetsart University, Bangkok 10900, Thailand \\ ${ }^{2}$ Department of Companion Animal Clinical Sciences, Faculty of Veterinary Medicine, Kasetsart University, \\ Nakhon Pathom 73140, Thailand \\ ${ }^{3}$ Department of Physiology, Faculty of Veterinary Medicine, Kasetsart University, Bangkok 10900, Thailand \\ ${ }^{4}$ Ophthalmology Clinic, Kasetsart University Veterinary Teaching Hospital, Faculty of Veterinary Medicine, \\ Kasetsart University, Bangkok 10900, Thailand \\ *Corresponding author e-mail: prasroedsangsudara@gmail.com
}

Received 13 August 2019; received in revised form 2 May 2020; accepted 3 May 2020

\begin{abstract}
Uveitis associated with Ehrlichia canis or Anaplasma platys infections were reported in dogs. However, only two E. canis-infected dogs with hypergammaglobulinemia showed acute blindness were reported. There were limited data of the species of Ehrlichia or Anaplasma and the alteration of serum protein fractions in infected dogs. Thus, the species of causative pathogen were investigated and compared the serum protein fractions between infected dogs associated with anterior uveitis and panuveitis in clinical situations. All 103 studied dogs were brought into the ophthalmology clinic which each dog showed signs of unilateral or bilateral uveitis related to ehrlichial infection. Dogs were divided into anterior uveitis and panuveitis groups. The species of Ehrlichia or Anaplasma were identified using nested-PCR based on the 16S rRNA gene and DNA sequencing from blood samples. The serum protein fractions were analyzed using electrophoresis. Fifty-eight dogs (56.31\%) were positive of which $E$. canis and A. platys were detected in 51 and 7 dogs, respectively. The total serum protein and globulin levels were higher in the infected dogs associated with panuveitis than anterior uveitis while the albumin levels were significantly lower in the panuveitis group. The A/G ratios significantly decreased in both groups. Gamma globulin was detected at high levels in both groups while beta globulin significantly increased in the panuveitis group. Hypergammaglobulinemia was detected in 76.92 and $90.90 \%$ of infected dogs associated with anterior uveitis and panuveitis, respectively. Most of the infected dogs associated with panuveitis showed significantly levels of hyperproteinemia, hyperbetaglobulinemia and hypergammaglobulinemia compared with anterior uveitis group. E. canis was found as the major pathogen in infected dogs associated with uveitis in this study.
\end{abstract}

\section{INTRODUCTION}

Ehrlichia and Anaplasma are obligatory intracellular alpha-proteobacteria. In Thailand, based on molecular techniques, only three species have been reported in infected dogs: Ehrlichia canis, Anaplasma platys and Anaplasma phagocytophilum (formerly Ehrlichia equi or Ehrlichia phagocytophila) (Suksawat et al., 2001; Pinyoowong et al., 2008; Jirapattharasate et al., 2012; Saeng-Chuto et al., 2016;
Kaewmongkol et al., 2017; Piratae et al., 2019). E. canis, A. platys and A. phagocytophilum reside within the cytoplasm of the monocyte, platelet and neutrophil, respectively, as tick-borne pathogens which are transmitted by the ixodid tick with worldwide distribution. A. phagocytophilum also causes human granulocytic anaplasmosis (HGA) and this pathogen spreads the disease in several animals, including horse, sheep and dog (Severo et al., 2012). However, only E. canis 
and A. platys infections have been reported as pathogens associated with uveitis in dogs (Massa et al., 2002; Saeng-Chuto et al., 2016). E. canis infection causes canine monocytic ehrlichiosis and appears in three stages: acute, subclinical and chronic which may be obvious by fever, depression, lymphadenopathy, splenomegaly, anemia, leukopenia and thrombocytopenia (Harrus et al., 1999; Skotarczak, 2003). The ocular signs are a common feature of the disease and can be presented in all stages (Leiva et al., 2005). The most common ocular disorders from $E$. canis infection include hyphema, anterior uveitis, panuveitis, optic neuritis, retinal hemorrhage and retinal detachment. Substantial levels of anterior uveitis (29.40-39.47\%) and posterior uveitis (44.12-64.7\%) with retinal detachment leading to acute blindness in E. canisinfected dogs have been reported (Leiva $e t$ al., 2005; Saeng-Chuto et al., 2016). A. platys can cause the clinical signs compatible with canine erhlichiosis (hemorrhagic manifestation and thrombocytopenia) in infected dogs but generally it is mild-tomoderate clinical signs (Abarca et al., 2007). A. platys was also reported as the etiology of both anterior and posterior uveitis in infected dogs (Glaze \& Gaunt, 1986; Saeng-Chuto et al., 2016).

Biochemical abnormalities in dogs infected with $E$. canis have been mentioned. From the previous studies, serum protein fractions analyses using electrophoresis showed hypoalbuminemia, hyperglobulinemia and hypergammaglobulinemia in infected dogs but the ocular signs were not mentioned in these studies (Breitschwerdt $e t$ al., 1987; Harrus et al., 1996). Moreover, the association between hyperproteinemia with hypergammaglobulinemia and panuveitis leading to acute blindness in E. canisinfected dogs were reported. Serum protein electrophoresis of two Labrador retrievers revealed monoclonal gammopathy and hypoalbuminemia (Harrus et al., 1998; Gould et al., 2000). To the best of our knowledge, a wider investigation for an association between serum protein fractions and the type of uveitis (anterior uveitis or panuveitis) has never been reported. Thus, the aims of the present study were to investigate the species of Ehrlichia and Anaplasma causing uveitis in clinical situations and to compare the serum protein fractions between infected dogs associated with anterior uveitis and panuveitis.

\section{MATERIALS AND METHODS}

\section{Animal selection and criteria}

One hundred and three dogs were brought into the ophthalmology clinic of a veterinary teaching hospital. Each dog showed signs of unilateral or bilateral uveitis related to ehrlichial infection which had been screened by the SNAP 4Dx test (IDEXX Laboratories, USA) or the dogs were suspected of having Ehrlichia or Anaplasma infections. Dogs were divided into two groups according to ocular signs, defined as anterior uveitis ( $\mathrm{n}=$ 41) and panuveitis $(n=62)$. All dogs fulfilled the 3 criteria of (1) having no history of ocular trauma (2) having no systemic diseases and neoplasia and (3) having no dehydration status. Control dogs were selected from 20 healthy dogs all of which were blood donors. Blood samples were collected from cephalic or saphenous veins and kept in EDTA tubes and clotted blood tubes (Fushino ${ }^{\circledR}$, Japan) for PCR assay and serum protein analysis, respectively. This study was approved by the Animal Experimental Committee of Kasetsart University (ACKU 59-VET-007).

\section{DNA extraction}

Blood samples (100 $\mu \mathrm{l}$ each) were lyzed with $600 \mu \mathrm{l}$ of denaturing solution (4 M guanidinium thiocyanate, $25 \mathrm{mM}$ sodium citrate, $\mathrm{pH}$ 7.0, 0.1 M 2-mercaptoethanol, $0.5 \%$ N-lauroylsarcosine), added with proteinase $\mathrm{K} 20 \mu \mathrm{l}$ and shaken for $5 \mathrm{~min}$. DNA was extracted using phenol-chloroform extraction and then precipitated in absolute ethanol, as previously described (Sambrook $\&$ Russell, 2001). DNA products were resuspended in TE buffer (50 mM Tris, pH 8.0, $1 \mathrm{mM}$ EDTA) and stored at $-20^{\circ} \mathrm{C}$ until use.

\section{Nested-PCR and DNA sequencing}

DNA products were used as a template to amplify the 16S rRNA gene of the species of 
Ehrlichia or Anaplasma using nested-PCR as previously described (Saeng-Chuto et al., 2016). The first PCR, primers EF: 5'TTGTA GCTAACGCGTTAAGCACT-3' and ER: 5'AACTCGAAGCTGGTGYGCYAACC-3' amplified a 551-bp region. The second PCR, primers IEF: 5'-GTTCGGCTGGAYCTYRCA CAGGT-3' and IER: 5'-CTGMAACTCGAGAG CATGAAGTC-3' amplified a 310-bp region of the 16s rRNA gene. In brief, the thermal cycling conditions for both PCR reactions were $94^{\circ} \mathrm{C}$ for $5 \mathrm{~min}, 45$ cycles of $\left[94^{\circ} \mathrm{C}\right.$ for 20 sec, $57^{\circ} \mathrm{C}$ for $20 \mathrm{sec}$, and $72^{\circ} \mathrm{C}$ for $40 \mathrm{sec}$, and the final extension $72^{\circ} \mathrm{C}$ for $10 \mathrm{~min}$. The positive control consisted of DNA from blood samples of dogs known to be naturally infected by E. canis and A. platys. Both PCR protocols were processed in a MyCycler ${ }^{\mathrm{TM}}$ Thermal Cycler (BioRad Laboratories, USA).

Babesia canis infection was also checked using PCR assay. Mixed infection between $E$. canis or A. platys and B. canis can occur naturally in dogs. DNA amplification of $B$. canis was performed using the specific primers Can172F: 5'-GTTTATTAG TTTGAAACCCGC-3' and Can626R: 5'-GAA CTCGAAAAAGCCAAACGA-3' to amplify PCR product approximately 550-bp. Two microliters of DNA extract from each sample was used as the template DNA for PCR in a final volume of $25 \mathrm{\mu l}$. The PCR conditions followed the protocol as previously described with an annealing temperature at $55^{\circ} \mathrm{C}$ and 35 cycles (Inokuma et al., 2004). Twenty microliters of amplified nested-PCR product of Ehrlichia and PCR product of B. canis were added to the $5 \mu \mathrm{l}$ of $6 \mathrm{X}$ loading buffer and loaded in $1.5 \%$ agarose (SeaKem ME:FMC, USA) gel electrophoresis for 40 min. Amplicons were processed using UltraClean $^{\text {TM }}$ GelSpin DNA purification Kit (MO BIO LABORATORIES Inc., USA) and submitted for sequencing ( $1^{\text {st }}$ Base Laboratory, Malaysia). DNA sequences were compared for the similarity of the nucleotide base with the genomic database in Genbank using the BLAST algorithm.

\section{Total protein level and serum protein electrophoresis}

PCR-positive samples for Ehrlichia or Anaplasma infection were randomly selected for the study of serum protein electrophoresis. Serum samples in clotted blood tubes were centrifuged at $978 \mathrm{xg}$ for $5 \mathrm{~min}$ and then sera were harvested and stored at $-40^{\circ} \mathrm{C}$ until use. The serum protein concentration was determined using spectrophotometry following the protocol of the Bradford method. The separation of protein fractions was performed using 13 and 22 serum samples of infected dogs associated with anterior uveitis and panuveitis, respectively and 20 serum samples of the control group using the cellulose acetate electrophoresis Helena system (Helena Laboratories 2001, USA) with TRIS-barbital-sodium barbital buffer $\mathrm{pH} 8.8$ (Electra ${ }^{\circledR}$ HR buffer, Helena, USA). Human serum protein standard was used as control sera in a separated membrane (Helena, USA). The electrophoresis was performed for 15 min at $180 \mathrm{~V}$ and then moved for dyeing in Ponceau S staining solution: serum protein electrophoresis fractions were analyzed using the Image Lab software (BioRad Laboratories, USA).

\section{Statistical Analysis}

The Tukey-Kramer Test and Dunn's Test Statistical System (NCSS) ver. 2000 (Kaysville, USA) programs were used to compare the relationship between the concentration of serum protein fractions and ocular signs (anterior uveitis/panuveitis). A $p$-value $\leq 0.05$ was considered as statistically significant. The results were presented as the mean \pm standard deviation.

\section{RESULTS}

In total, 58/103 dogs (36 males and 22 females) or $56.31 \%$ were positive for Ehrlichia or Anaplasma infection (Table 1). The age range of infected dogs was 0.5 to 14 years, with a mean of 6.47 years. DNA sequencings showed 47/58 (81.03\%) and $7 / 58$ (12.07\%) positive dogs were infected with $E$. canis and A. platys, respectively. $B$. canis infection was found in four Ehrlichia-positive dogs (4/58, 6.9\%). The mixed infections between $E$. canis and $B$. canis were only found in the present study. 
Table 1. Results of PCR and DNA sequencing of 58 positive dogs grouped by the type of uveitis

\begin{tabular}{lccc}
\hline \multirow{2}{*}{ Group } & \multicolumn{3}{c}{ Number of infected dogs } \\
\cline { 2 - 4 } & E. canis $(\%)$ & A. platys (\%) & B. canis and E. canis $(\%)$ \\
\hline Anterior uveitis $(\mathrm{n}=41)$ & $17(41.46)$ & $4(9.75)$ & $2(4.87)$ \\
Panuveitis $(\mathrm{n}=62)$ & $30(48.38)$ & $3(4.83)$ & $2(3.22)$ \\
\hline Total $(\mathrm{n}=103)$ & $47(45.63)$ & $7(6.79)$ & $4(3.88)$ \\
\hline
\end{tabular}

Dogs with this mixed infection were excluded from the study of serum protein fraction analysis. Both of $A$. platys and E. canis caused anterior uveitis and panuveitis in the present study. The ocular disorders in infected dogs associated with panuveitis were hyphema, vitreous hemorrhage, retinal hemorrhage and retinal detachment.

The mean values of total serum proteins significantly increased in infected dogs associated with anterior uveitis or panuveitis compared with the control dogs. Comparison between the two groups of infected dogs indicated that the total serum protein was also significantly higher in infected dogs associated with panuveitis than anterior uveitis. Mean values of albumin concentration were significantly low in infected dogs associated with panuveitis compared with the control dogs. There was no significant difference in the albumin level between infected dogs associated with anterior uveitis and the control groups. The mean values of globulin concentration were significantly higher in infected dogs associated with anterior uveitis or panuveitis compared with the control group. Moreover, the level of globulin in infected dogs associated with panuveitis was significant higher than for anterior uveitis $(\mathrm{p} \leq 0.05)$. The albumin/globulin $(\mathrm{A} / \mathrm{G})$ ratio significantly decreased in both groups of infected dogs associated with uveitis compared with the control group (Table 2).

Comparison between groups of infected dogs associated with anterior uveitis or panuveitis and the control dogs indicated that the mean concentration values of gamma globulins were statistically higher $(p \leq 0.05)$. Hypergammaglobulinemia was detected in $10 / 13(76.92 \%)$ and $20 / 22(90.90 \%)$ of the infected dogs associated with anterior uveitis and panuveitis, respectively (Figure 1). The mean concentration values of beta globulin significantly increased $(\mathrm{p} \leq 0.05)$ in infected dogs associated with panuveitis compared with anterior uveitis or the control groups. Elevated levels of beta globulin were detected in 14/22 (63.63\%) of the infected dogs associated with panuveitis. However, there was no statistical difference of the concentration levels of alpha1 or alpha2 globulins between the two groups of infected dogs associated with uveitis and the control dogs (Table 2 and Figure 1) ( $p>0.05)$. All infected dogs with hyperglobulinemia showed polyclonal gammopathy (Figure 2).

\section{DISCUSSION}

From the present study, 23 and 35 infected dogs were associated with anterior uveitis and panuveitis, respectively. All infected dogs were in the acute or subclinical stages. Only E. canis and A. platys were detected in infected dogs: the other species of Ehrlichia (E. ewingii, E. chaffeensis) and A. phagocytophilum were not detected. The prevalence of infections with $E$. canis or A. platys were found in male dogs more than female dogs which are similar to the previous results in Thailand (Saeng-Chuto et al., 2016; Piratae et al., 2019). E. canis was a major pathogen for anterior uveitis and panuveitis of dogs in the present study. This is similar to previous studies reporting that only E. canis and $A$. platys infections can cause uveitis in a clinical situation (Glaze \& Gaunt, 1986; Leiva et al., 2005; Saeng-Chuto et al., 2016). The ocular disorders in E. canis or A. platysinfected dogs associated with panuveitis were similar to the previous report (SaengChuto et al., 2016). However, the infection 
Table 2. Concentrations of total serum protein, albumin, globulin, A/G ratio, $\alpha_{1^{-}}, \alpha_{2}$, $\beta$ - and $\gamma$-globulin presented as mean \pm SD of 13 and 22 infected dogs associated with anterior uveitis and panuveitis, respectively, and 20 normal control dogs. The different lowercase superscript letters indicate statistically significant differences at $p \leq 0.05$

\begin{tabular}{lccc}
\hline Parameter & Control & Anterior uveitis & Panuveitis \\
\hline Total protein (g/dl) & $6.23 \pm 0.37^{\mathrm{a}}$ & $7.16 \pm 0.87^{\mathrm{b}}$ & $8.02 \pm 1.15^{\mathrm{c}}$ \\
Albumin $(\mathrm{g} / \mathrm{dl})$ & $3.85 \pm 0.40^{\mathrm{a}}$ & $3.20 \pm 1.21^{\mathrm{a}}$ & $2.67 \pm 0.93^{\mathrm{b}}$ \\
Globulin $(\mathrm{g} / \mathrm{dl})$ & $2.38 \pm 0.45^{\mathrm{a}}$ & $3.96 \pm 1.38^{\mathrm{b}}$ & $5.35 \pm 1.69^{\mathrm{c}}$ \\
A/G ratio & $1.72 \pm 0.60^{\mathrm{a}}$ & $1.03 \pm 0.76^{\mathrm{b}}$ & $0.62 \pm 0.46^{\mathrm{b}}$ \\
$\alpha_{1^{-} \text {-globulin }(\mathrm{g} / \mathrm{dl})}$ & $0.12 \pm 0.07^{\mathrm{a}}$ & $0.15 \pm 0.07^{\mathrm{a}}$ & $0.11 \pm 0.05^{\mathrm{a}}$ \\
$\alpha_{2^{-} \text {-globulin }(\mathrm{g} / \mathrm{dl})}$ & $0.66^{\mathrm{a}} \pm 0.21^{\mathrm{a}}$ & $0.96 \pm 0.54^{\mathrm{a}}$ & $0.71 \pm 0.32^{\mathrm{a}}$ \\
$\beta$-globulin $(\mathrm{g} / \mathrm{dl})$ & $1.06 \pm 0.28^{\mathrm{a}}$ & $0.85 \pm 0.34^{\mathrm{a}}$ & $1.53 \pm 0.81^{\mathrm{b}}$ \\
$\gamma$-globulin $(\mathrm{g} / \mathrm{dl})$ & $0.53 \pm 0.23^{\mathrm{a}}$ & $2.00 \pm 1.52^{\mathrm{b}}$ & $3.00 \pm 1.56^{\mathrm{b}}$ \\
\hline
\end{tabular}

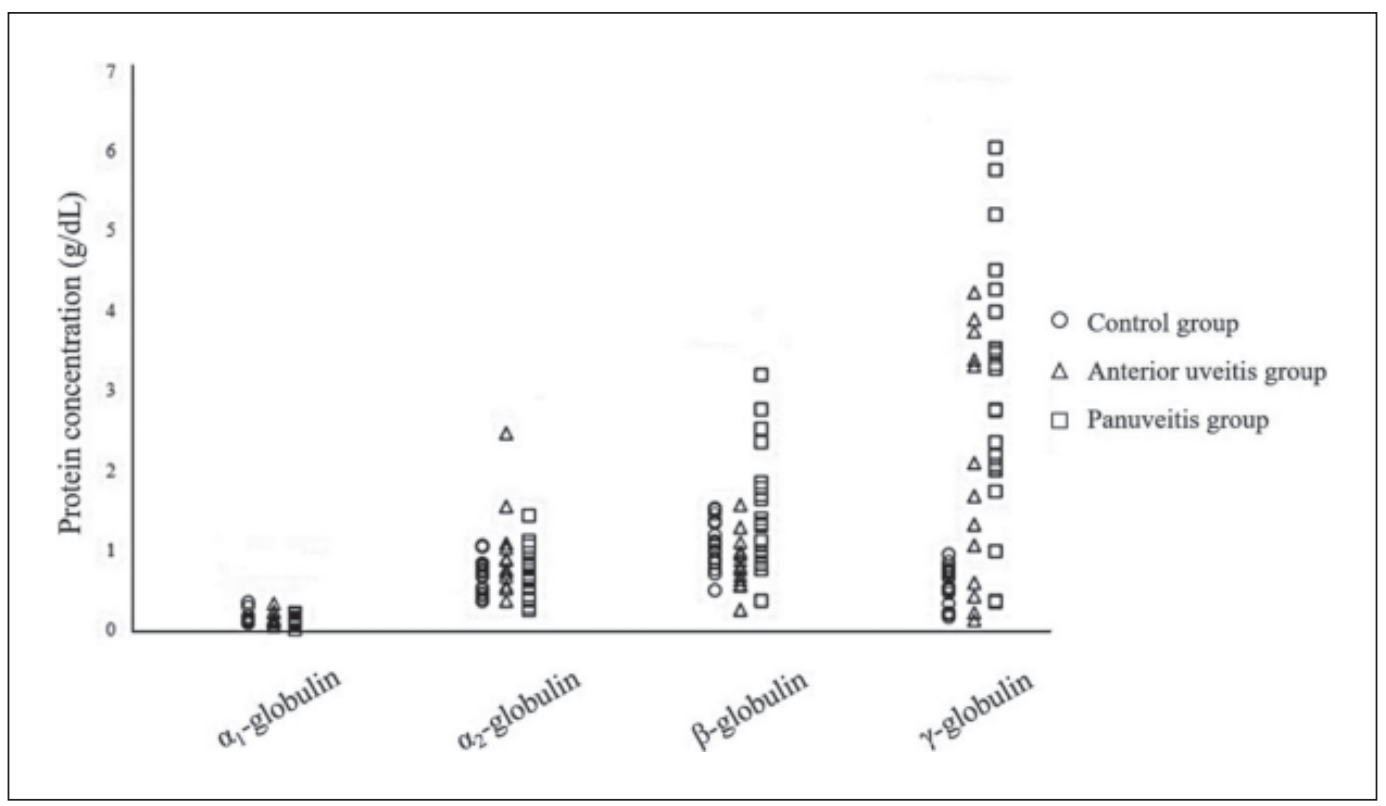

Figure 1. Concentrations of four serum protein fractions of 13 and 22 Ehrlichia-infected dogs associated with anterior uveitis and panuveitis, respectively, and 20 normal control dogs.

rate in the present study using nested-PCR detection was $56.31 \%$ which was lower than the suspected case numbers with canine ehrlichiosis or anaplasmosis. It is possible that the detection of ehrlichial DNA in blood may result in a lower succession than expected, as spleen aspiration is a good source of DNA for PCR because the spleen is probably the last place to harbor $E$. canis in the subclinical stage (Harrus et al., 1999, 2004). E. canis seems to persist longer in splenic macrophages more than blood monocytes. Mixed infections between $E$. canis and B. canis or A. platys with B. canis can naturally occur in dogs because these pathogens are tick-borne, sharing the same vector in Thailand. In the present study, the mixed infections between $E$. canis and $B$. canis was detected at a low percentage which was similar to the previous report that identified this mixed infections in only $2.5 \%$ of studied dogs using nested-PCR (Piratae 


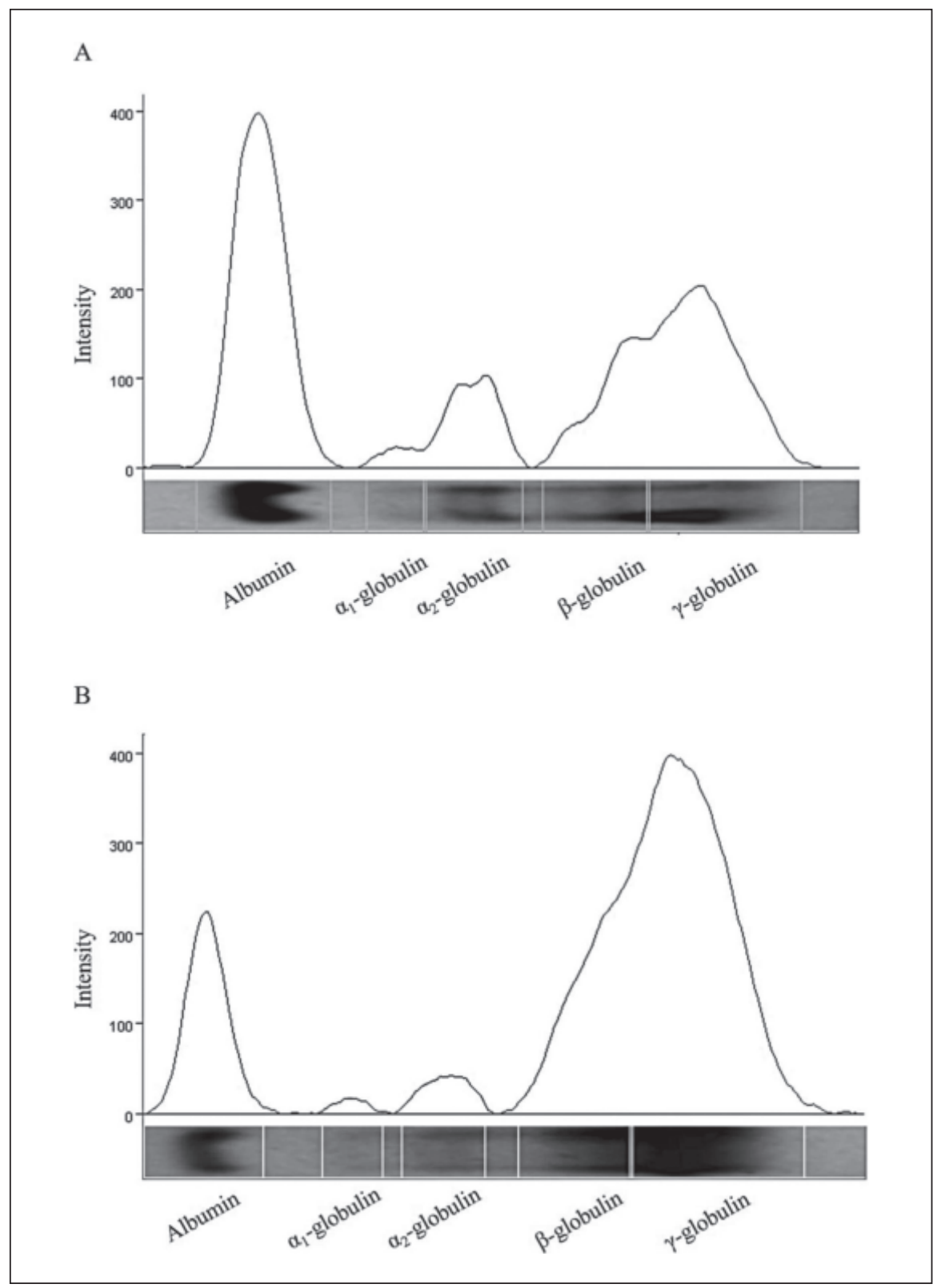

Figure 2. Serum protein electrophoresis from two dogs presenting with anterior uveitis (A) and panuveitis (B) associated with E. canis infection. Serum protein pattern shows the elevation of beta- and gamma globulins, particularly in the panuveitis group. Polyclonal gammopathy was detected in these dogs.

et al., 2015). Dogs with E. canis and B. canis infections were excluded from the serum protein fraction analysis because $B$. canis infection could cause serum protein alterations including, hypergammaglobulinemia, hyperbetaglobulinemia and hypoalbuminemia (Solona-Gallego et al., 2008).
Albumin and globulin $\left(\alpha_{1}, \alpha_{2}, \beta, \gamma\right)$ are the major serum proteins in dogs. Hypergammaglobulinemia in E. canis or A. platys-infected dogs indicates an increase in immunoglobulin production. Hypoalbuminemia associated with acute stage of $E$. canis infection in dogs was reported which may be attributable primarily to increase renal loss of protein, or 
blood loss, rather than decreased hepatic synthesis (Codner \& Maslin, 1992; Harrus et al., 1999). The decrease in albumin concentration may act as a compensatory mechanism for hyperglobulinemia to maintain the oncotic pressure. In general, a normal range for the $\mathrm{A} / \mathrm{G}$ ratio is $0.8-2.0$ in adult dogs (Klaassen, 1999). The A/G ratio was significantly low in infected dogs associated with uveitis, particularly in the panuveitis group for which the $\mathrm{A} / \mathrm{G}$ ratio was lower than 1 , indicating that the infection or disease is present in these dogs. Moreover, hyperbetaglobulinemia was detected in infected dogs associated with panuveitis. Beta globulin (beta1 and beta2) is composed of C-reactive protein (CRP), transferrin, and complement factors among other things. Unfortunately, the type of beta globulin was not identified in the present study. However, it is possible that elevated beta globulins in panuveitis groups come from the increased production of CRP. Increased concentrations of CRP in blood were reported in dogs infected with $E$. canis at the acute stage of infection (Rikihisa et al., 1994; Shimada et al., 2002). CRP is synthesized in the liver following tissue damage caused by infection or inflammation. It was reported to causes the activation of macrophages, it may help to kill $E$. canis in the macrophages of infected dogs, controlling the infection at a subclinical stage (Rikihisa et al., 1994).

Hyperproteinemia, hypergammaglobulinemia and hyperbetaglobulinemia may result in increased blood viscosity in E. canis or A. platys-infected dogs. Serum hyperviscosity increases the oncotic pressure in blood vessels and probably results in ischemic changes and hemorrhage in the posterior uvea. The most important gamma globulins are immunoglobulins. Hypergammaglobulinemia in infected dogs may come from the production of antibodies including anti- $E$. canis antibodies, antiplatelet antibodies (APA) and antinuclear antibodies (Harrus et al., 1999; Smith et al., 2004). A high level of immunoglobulin may result in the deposition of immune complexes in ocular blood vessel walls and subsequently cause vasculitis (Panciera et al., 2001). The appearance of free $E$. canis antigen in the plasma has been previously reported which presented initially at 15-20 days after infection (Waner et al., 1996). High titers of antinuclear antibodies were detected in dogs naturally infected with $E$. canis (Smith $e t$ al., 2004). Moreover, thrombocytopenia was detected in 29/33 (87.87\%) of the infected dogs associated with panuveitis in the present study (data not shown). There are many mechanisms of thrombocytopenia, including immune-mediated platelet destruction, hypersplenism, vascular endothelial damage and direct infection of platelets by A. platys (Harrus et al., 1998). APA production in dogs after experimental infection with $E$. canis supported the hypothesis that immune-mediated platelet destruction may contribute to the pathogenesis of thrombocytopenia (Waner et al., 1995; Harrus et al., 1999). Serum hyperviscosity, vasculitis and thrombocytopenia could result in intraocular hemorrhage in E. canis or A. platys-infected dogs in the present study. Thus, in the future, the detection and levels of anti-Ehrlichia antibodies, antinuclear antibodies, APA and the type of beta globulins should be investigated in infected dogs associated with uveitis, particularly in dogs with intraocular hemorrhage.

In the present study, most of the $E$. canis or A. platys-infected dogs associated with anterior uveitis or panuveitis showed hypergammaglobulinemia in which polyclonal gammopathy was detected. This accords with previous reports that most of the studied dogs infected with $E$. canis had hypergammaglobulinemia with polyclonal gammopathy, while monoclonal gammopathy rarely occurred (Harrus et al., 1996, 1999). However, two Labrador retrievers were reported to have acute blindness associated with monoclonal gammopathy induced by E. canis infection (Harrus et al., 1998; Gould et al., 2000).

In conclusion, higher levels of total serum protein, gamma- and beta globulins were detected in E. canis or A. platysinfected dogs associated with uveitis, particularly with panuveitis. These higher 
levels are probably associated with panuveitis, intraretinal or subretinal hemorrhages as well as retinal detachment leading to acute blindness in dogs.

\section{Competing interests}

The authors have no competing interests to declare.

\section{Author's contributions}

B.N., S.P. and P.K. designed the experiment. B.N. and A.T. carried out blood sample collection. S.P. performed laboratory work (PCR, serum protein electrophoresis). C.K. carried out DNA sequencing and analysis. B.N. and S.P. prepared and revised the manuscript. All authors read and approved the final manuscript.

Acknowledgements. The present study was financially supported by a research grant from the Kasetsart University Research and Development Institute (KURDI), Thailand. We would like to thank the owners of dogs for their permission to collect blood samples.

\section{REFERENCES}

Abarca, K., López, J., Perret, C., Guerrero, J., Godoy, P., Veloz, A., Valiente-Echeverría, F., León, U., Gutjahr, C. \& Azócar, T. (2007). Anaplasma platys in dogs, Chile. Emerging Infectious Diseases 13: 13921394.

Breitschwerdt, E.B., Woody, B.J., Zerbe, C.A., De Buysscher, E.V. \& Barta, O. (1987). Monoclonal gammopathy associated with naturally occurring canine ehrlichiosis. Journal of Veterinary Internal Medicine 1: 2-9.

Codner, E.C. \& Maslin, W.R. (1992). Investigation of renal protein loss in dogs with acute experimentally induced Ehrlichia canis infection. American Journal of Veterinary Research 53: 294-299.

Glaze, M.B. \& Gaunt, S.D. (1986). Uveitis associated with Ehrlichia platys infection in a dog. Journal of the American Veterinary Medical Association 189: 916-917.
Gould, D.J., Murphy, K., Rudorf, H. \& Crispin, S.M. (2000). Canine monocytic ehrlichiosis presenting as acute blindness 36 months after importation into the UK. Journal of Small Animal Practice 41: 263-265.

Harrus, S., Waner, T., Avidar, Y., Bogin, E., Peh, H. \& Bark, H. (1996). Serum protein alterations in canine ehrlichiosis. Veterinary Parasitology 66: 241-249.

Harrus, S., Ofri, R., Aizenberg, I. \& Waner, T. (1998). Acute blindness associated with monoclonal gammopathy induced by Ehrlichia canis infection. Veterinary Parasitology 78: 155-160.

Harrus, S., Waner, T., Bark, H., Jongejan, F. \& Cornelissen, A.W.C.A. (1999). Recent advances in determining the pathogenesis of canine monocytic ehrlichiosis. Journal of Clinical Microbiology 37: 2745-2749.

Harrus, S., Kenny, M., Miara, L., Aizenberg, I., Waner, T. \& Shaw, S. (2004). Comparison of simultaneous splenic sample PCR with blood sample PCR for diagnosis and treatment of experimental Ehrlichia canis infection. Antimicrobial Agents and Chemotherapy 48: 4488-4490.

Inokuma, H., Yoshizaki, Y., Matsumoto, K., Okuda, M., Onishi, T., Nakagome, K. Kosugi, R. \& Hirakawa, M. (2004). Molecular survey of Babesia infection in dogs in Okinawa, Japan. Veterinary Parasitology 121: 341-346.

Jirapattharasate, C., Chatsiriwech, J., Suksai, P., Changbunjong, T., Rawangchue, T., Moonarmart, W. \& Sungpradit, S. (2012). Identification of Ehrlichia spp. in canines in Thailand. The Southeast Asian Jourmal of Tropical Medicine and Public Health 43: 964-968.

Kaewmongkol, G., Lukkana, N., Yangtara, S., Kaewmongkol, S., Thengchaisri, N., Sirinarumitr, T., Jittapalapong, S. \& Fenwick, S.G. (2017). Association of Ehrlichia canis, Hemotropic Mycoplasma spp. and Anaplasma platys and severe anemia in dogs in Thailand. Veterinary Microbiology 120: 195-200.

Klaassen, J.K. (1999). Reference values in veterinary medicine. Laboratory Medicine 30: 194-197. 
Leiva, M., Naranjo, C. \& Peña, M.T. (2005). Ocular signs of canine monocytic ehrlichiosis: A retrospective study in dogs from Barcelona, Spain. Veterinary Ophthalmology 8: 387-393.

Massa, K.L., Gilger, B.C., Miller, T.L. \& Davidson, M.G. (2002). Causes of uveitis in dogs: 102 cases (1989-2000). Veterinary Ophthalmology 5: 93-98.

Panciera, R.J., Ewing, S.A. \& Confer, A.W. (2001). Ocular histopathology of ehrlichial infections in the dog. Veterinary Pathology 38: 43-46.

Pinyoowong, D., Jittapalapong, S., Suksawat, F., Stich, R.W. \& Thamchaipenet, A. (2008). Molecular characterization of Thai Ehrlichia canis and Anaplasma platys strains detected in dogs. Infection, Genetics and Evolution 8: 433-438.

Piratae, S., Pimpjong, K., Vaisusuk, K. \& Chantan, W. (2015). Molecular detection of Ehrlichia canis, Hepatozoon canis and Babesia canis vogeli in stray dogs in Mahasarakham province, Thailand. Annals of Parasitology 61: 183-187.

Piratae, S., Senawong, P., Chalermchat, P., Harnarsa, W. \& Sae-chue, B. (2019). Molecular evidence of Ehrlichia canis and Anaplasma platys and the association of infections with hematological responses in naturally infected dogs in Kalasin, Thailand. Veterinary World 12: 131-135.

Rikihisa, Y., Yamamoto, S., Kwak, I., Iqbal, Z., Kociba, G., Mott, J. \& Chichanasiriwithaya, W. (1994). C-reactive protein and $\alpha 1$-acid glycoprotein levels in dogs infected with Ehrlichia canis. Journal of Clinical Microbiology 32: 912-917.

Saeng-Chuto, K., Thayananuphat, A., Sritrakoon, N. \& Nimsuphan, B. (2016). Thrombocytopenia and anemia related to retinal detachment in dogs infected with Ehrlichia canis and Anaplasma platys. Tropical Biomedicine 33: 519525.

Sambrook, J.F. \& Russell, D.W. (2001). Molecular cloning. In: A laboratory manual, $3^{\text {rd }}$ edition. New York: Cold Spring Harbour Laboratory Press, pp. A8.9-8.13.
Severo, M.S., Stephens, K.D., Kotsyfakis, M. \& Pedra, J.H.F. (2012). Anaplasma phagocytophilum: deceptively simple or simply deceptive? Future Microbiology 7: 719-731.

Shimada, T., Ishida, Y., Shimizu, M., Nomura, M., Kawato, K., Iguchi, K. \& Jinbo, T. (2002). Monitoring C-reactive protein in beagle dogs experimentally inoculated with Ehrlichia canis. Veterinary Research Communications 26: 171-177.

Skotarczak, B. (2003). Canine ehrlichiosis. Annals of Agricultural and Environmental Medicine 10: 137-141.

Smith, B.E., Tompkins, M.B. \& Breitschwerdt, E.B. (2004). Antinuclear antibodies can be detected in dog sera reactive to Bartonella vinsonii subsp. berkhoffii, Ehrlichia canis, or Leishmania infantum antigens. Journal of Veterinary Internal Medicine 18: 47-51.

Solona-Gallego, L., Trotta, M., Carli, E., Carcy, B., Caldin, M. \& Furlanello, T. (2008). Babesia canis canis and Babesia canis vogeli clinicopathological findings and DNA detection by means of PCR-RFLP in blood from Italian dogs suspected of tick-borne disease. Veterinary Parasitology 157: 211-221.

Suksawat, J., Pitulle, C., Arraga-Alvarado, C., Madrigal, K., Hancock, S.I. \& Breitschwerdt, E.B. (2001). Coinfection with three Ehrlichia species in dogs from Thailand and Venezuela with emphasis on consideration of $16 \mathrm{~S}$ ribosomal DNA secondary structure. Jourmal of Clinical Microbiology 39: 90-93.

Waner, T., Harrus, S., Weiss, D.J., Bark, H. \& Keysary, A. (1995). Demonstration of serum antiplatelet antibodies in experimental acute canine ehrlichiosis. Veterinary Immunology and Immunopathology 48: 177-182.

Waner, T., Rosner, M., Harrus, S., Naveh, A., Zass, R. \& Keysary, A. (1996). Detection of ehrlichial antigen in plasma of beagle dogs with experimental acute Ehrlichia canis infection. Veterinary Parasitology 63: 331-335. 